\title{
Penetrating keratoplasty for pseudophakic corneal oedema
}

\author{
J Kwartz, B Leatherbarrow, P Dyer, A E A Ridgway, A B Tullo
}

\begin{abstract}
Aims-The study was designed to investigate the results of penetrating keratoplasty (PK) for pseudophakic corneal oedema (PCO).

Methods-Retrospective analysis of 80 consecutive patients ( 82 eyes) who underwent PK for PCO between the years 1980-1992 with a minimum follow up of 12 months.

Results-PKs for PCO have accounted for as many as $\mathbf{2 0} \%$ of all grafts performed in the hospital in recent years. The interval between cataract extraction and PK ranged from 6 to 161 months (mean 51 months). The intraocular lens was removed in $45(55 \%)$, left in situ in 30 $(37 \%)$, and exchanged in seven $(8 \%)$ of cases respectively. Of the intraocular lenses involved $62 \%$ were iris supported, $31 \%$ angle supported, and $7 \%$ were posterior chamber lenses. Actuarial analysis shows graft survival to be $91 \%$ at 1 year and $86 \%$ at 2 years after surgery. The likelihood of graft survival was significantly enhanced by removal of the intraocular lens $(p<0 \cdot 01)$. A corrected Snellen visual acuity worse than $6 / 60$ was present in $36 \%$ of patients with a clear corneal graft. Ocular comfort was achieved in all patients with a clear corneal graft.

Conclusion-PK for PCO resulted in a disappointing visual result in a large proportion of patients. PK was, however, successful in relieving pain and corneal ulceration when present.

(Br f Ophthalmol 1995; 79: 435-438)
\end{abstract}

Pseudophakic corneal oedema (PCO) is a common indication for penetrating kerato-

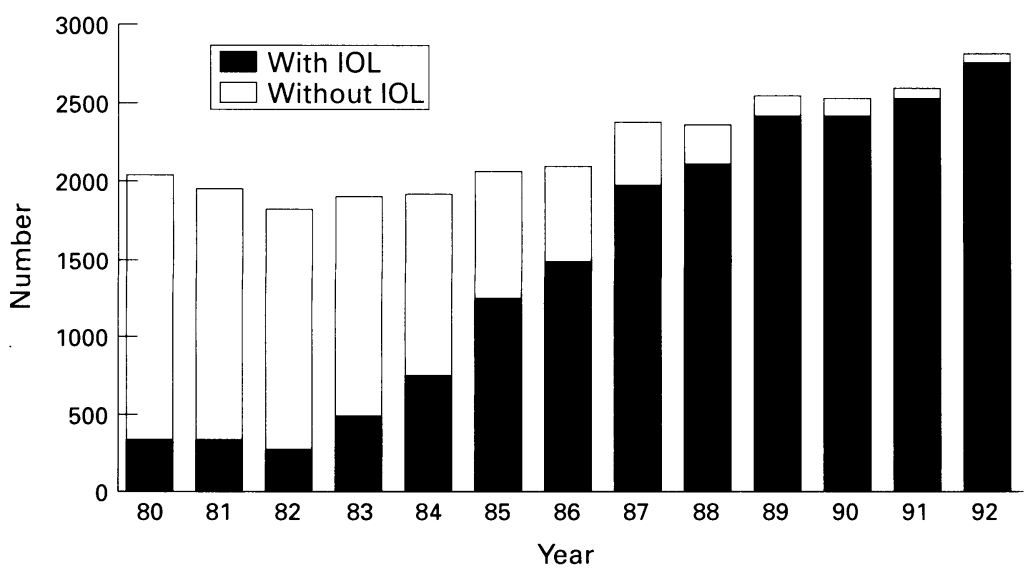

Figure 1 Cataract extractions at Manchester Royal Eye Hospital 1980-92. plasty (PK) in North America and in the United Kingdom. ${ }^{1-5}$ We have observed changes in the number of PKs performed for PCO in our hospital in the last decade and have analysed the outcome of the surgical treatment of PCO, which has received little attention in the British literature.

\section{Materials and methods}

The numbers of cataract extractions with and without intraocular lenses (IOL) performed at Manchester Royal Eye Hospital (MREH) for the years 1980-92 were established. The hospital records of all patients who underwent penetrating keratoplasty for PCO at $\mathrm{MREH}$ between March 1980 and May 1992 were reviewed. The records were analysed to determine the type of intraocular lens implanted and the time interval between IOL implantation and PK. The best corrected visual acuity after cataract extraction and subsequent visual results following PK were also analysed. The operative management of the intraocular lens was also correlated with visual outcome.

The annual number of cataract extractions with and without lens implantation is illustrated in Figure 1. This shows the remarkable increase in number of lens implants used during the $1980 \mathrm{~s}$

The proportion of PKs performed annually for PCO at the MREH increased during the 1980s until 1988. PKs for PCO are shown as a percentage compared with aphakic corneal oedema (ACO) and all other diagnoses for the years 1986-92 (Fig 2).

The intraocular lenses implanted at the time of cataract extraction are listed in Table 1.

The patient study included 82 eyes that underwent $\mathrm{PK}$ in 80 patients. The age range of the patients was 36 to 87 (mean 70 ) years. The sex distribution was 44 female and 38 male. There was an equal left and right distribution. Cataract surgery had been performed on all patients between 1970 and 1988. Sixty three patients $(77 \%)$ had significant ocular discomfort or pain, which was alleviated by a functioning corneal graft. Follow up of the patients ranged from 12 to 139 months with a mean of 46 months. Six patients were lost to follow up, and there were two deaths. The mean time from cataract surgery to penetrating keratoplasty ranged from 6 to 151 months with a mean of 51 months. Twenty eight $(34 \%)$ of the cataract extractions had been performed in other centres, while $54(66 \%)$ had been performed at MREH in which there were 12 recorded cases of vitreous loss at cataract surgery.

At the time of PK the intraocular lens was 


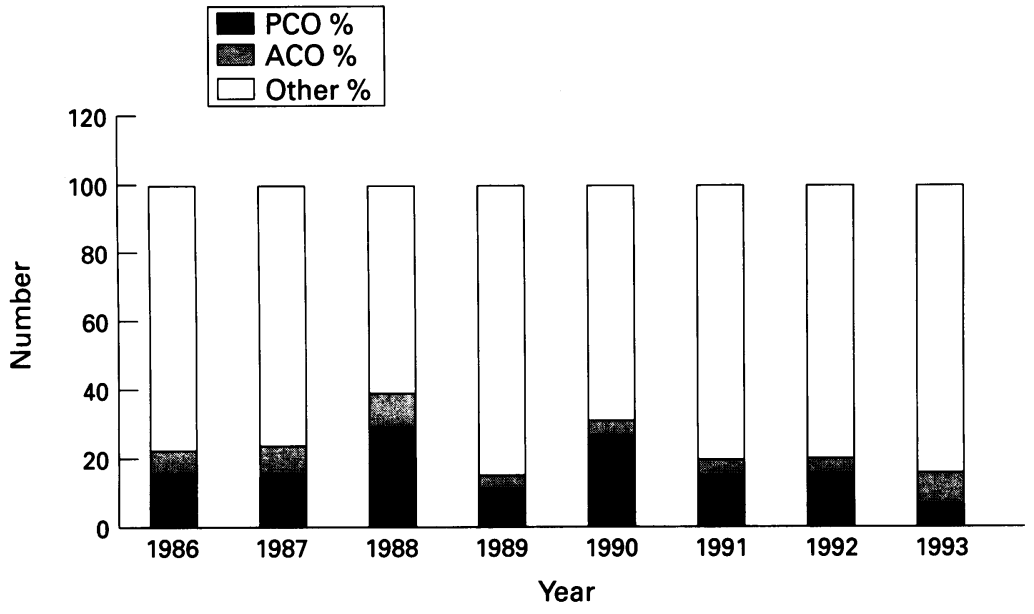

Figure 2 Percentage of penetrating keratoplasties performed annually at Manchester Royal Eye Hospital. PCO=pseudophakic corneal oedema; $A C O=$ aphakic corneal oedema.

removed in 45 eyes, retained in 30, and exchanged in the remaining seven eyes. Anterior vitrectomy and anterior segment reconstruction were performed as required at the time of the surgical procedure.

The type and source of the donor material used is shown in Table 2.

The suturing technique used for the PKs was as follows: 70 interrupted sutures; five continuous sutures; and seven continuous and interrupted combined.

Fifty six operations were performed under general anaesthesia and 26 under local anaesthesia.

\section{Results}

There were 23 graft failures; two were primary failures, both in fresh donor material; one graft was replaced because of remaining IOL instability and the need for anterior vitrectomy; five grafts failed as a result of identifiable rejection episodes. The remaining failures were due to endothelial insufficiency.

Removal of the IOL at the time of surgery significantly enhanced graft survival compared with eyes in which the IOL was left in situ. When lens exchange cases were included the difference in survival was even greater (Table 3).

Actuarial analysis shows graft survival to be $91.4 \%$ at 1 year with 82 eyes available for analysis and $85.7 \%$ at 2 years with 68 eyes available for analysis (Fig 3).

Of the 23 graft failures, 11 have been regrafted. Of these eight remain clear. Five of these patients have achieved a best corrected Snellen visual acuity of $6 / 36$ or better. The best corrected post cataract visual acuity - that is, before the onset of corneal decompensation, is useful in comparison with the post keratoplasty visual acuity. Figure 4 clearly indicates how often vision is irreversibly compromised.

\section{Table 2 Donor material used}

Fresh $<30$ hours after donor death 1980-86 Organ culture (Bristol Eye Bank) 1986-92

Organ culture (Manchester Eye Bank) 1988-92

Total
Table 3 Intraocular lens disposal at time of penetrating keratoplasty (PK)

\begin{tabular}{lll}
\hline & Lens number & Number of $P K$ failures \\
\hline Lens removed & 45 & 14 \\
Lens left in situ & 30 & 9 \\
Lens exchanged & 7 & 0 \\
\hline PK failure is statistically significant if the lens is left in situ, \\
p $<0.05\left(\chi^{2}\right)$. Including lens exchange, $\mathrm{p}<0.01$.
\end{tabular}

The various causes of a final best corrected visual acuity below $6 / 60$ are illustrated in Table 4.

\section{Discussion}

Pseudophakic corneal oedema is a common indication for PK in the USA, Australia, Denmark, and the UK. ${ }^{1-6}$ The Corneal Transplant Follow up Study has reported that $15 \%$ of 3184 grafts performed from 1987 to 1991 were for PCO. ${ }^{1}$ Indeed, one study has shown that PCO is the commonest indication for PK which subsequently requires further keratoplasty. ${ }^{7}$ The incidence of PKs performed for this condition may not, however, directly correlate with the overall prevalence of $\mathrm{PCO}$ in the pseudophakic community. The extent of the problem could only be elicited if all patients with PCO are accounted for, irrespective of whether PK is performed or not. ${ }^{8}$

The IOLs reported to be associated with PCO reflect the IOL implant trends previously reported in the USA $^{9}$ where an epidemic of PCO related to certain styles of lenses and surgical techniques has occurred. ${ }^{10}$ In centres such as Zurich and Belfast, where restraint was shown and few offending lenses were implanted the PCO epidemic has been avoided. ${ }^{11} 12$ Although iris and angle supported lenses are known to be the lenses most likely to be involved in PCO we have been unable to establish the relative risk because our records do not record the total numbers of all lens types used during the 1980 s. It should be remembered that the lens itself may not be the sole factor in the causation of PCO ${ }^{13}$ Other potential causes of this problem are varied and include pre-existing endothelial insufficiency and technical difficulties at the time of cataract surgery. Our data (Fig 2), showing a gradual fall in the incidence of ACO, suggest intracapsular surgery itself was damaging to the endothelium. The development of extracapsular cataract surgery and posterior chamber lens implantation has occurred at a time of a fall in incidence of PCO despite the huge numbers of IOLs now implanted.

Controversy has surrounded the best management of the IOL during surgery for PCO. Waring has outlined a management strategy for patients with PCO. ${ }^{10}$ The suggestions include a full anterior segment reconstruction with removal of the intraocular lens applying the maxim of 'when in doubt, take it out'. If possible the eye should then be rendered pseudophakic. In our study the IOL was removed in $45(55 \%)$ and exchanged in only seven $(8 \%)$, the lens being retained in the remaining 30 cases (37\%). 


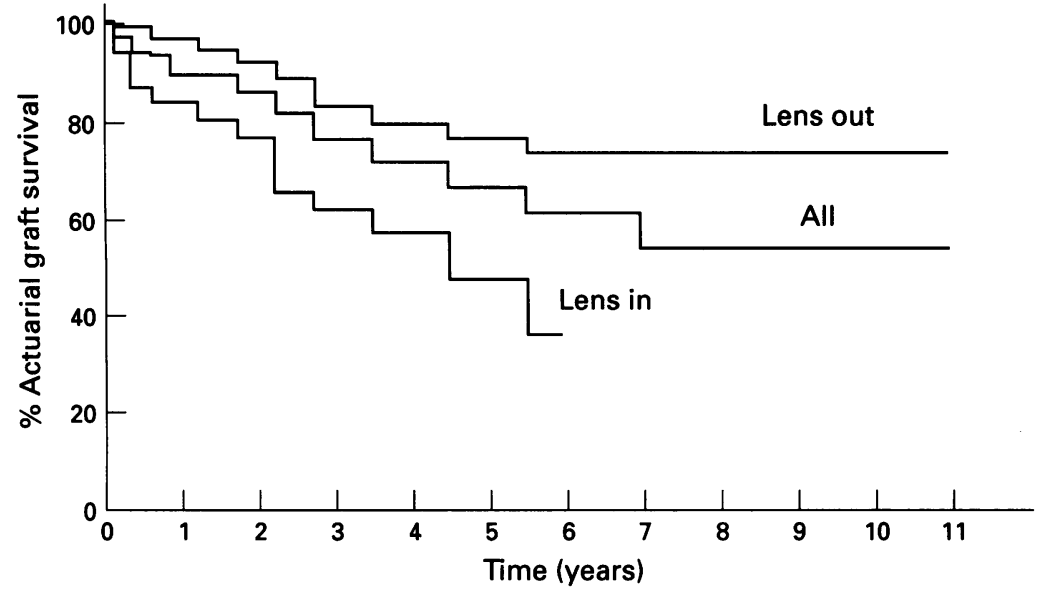

Figure 3 Kaplan-Meier survival probability curve of corneal grafts following penetrating keratoplasty for pseudophakic corneal oedema.

The removal of the IOL is not without hazard and there is, more often than not, a need to carefully remove vitreous from around the IOL and perform an anterior vitrectomy. ${ }^{14}$ There is, however, an increased incidence of retinal detachment and cystoid macular oedema associated with the removal of the lens and anterior vitreous clearance, ${ }^{15}$ particularly with closed loop AC IOLs. ${ }^{16} 17$ Kornmehl et al have reported favourable visual results 2 years after $P K$ and exchange of a closed loop AC IOL for a single flexible tripod AC IOL with $52.5 \%$ of patients achieving a postoperative best corrected visual acuity of $20 / 40$ or better. ${ }^{18}$ Although modern AC IOLs with open loops are generally accepted to be safe with regard to the cornea, there is a trend towards implantation of an IOL behind the iris. The aim is to position the loops of the PC IOL in the ciliary sulcus and stabilise the lens position with transcleral or iris sutures. ${ }^{19-22}$ This technique, however, is not without complications. ${ }^{23}$ The results of this study and other published series have led to a subsequent increase in our hospital of lens exchange with $\mathrm{PC}$ and $\mathrm{AC}$ implantation during surgery for PCO since 1990 . We have been unable to conclude from our own series

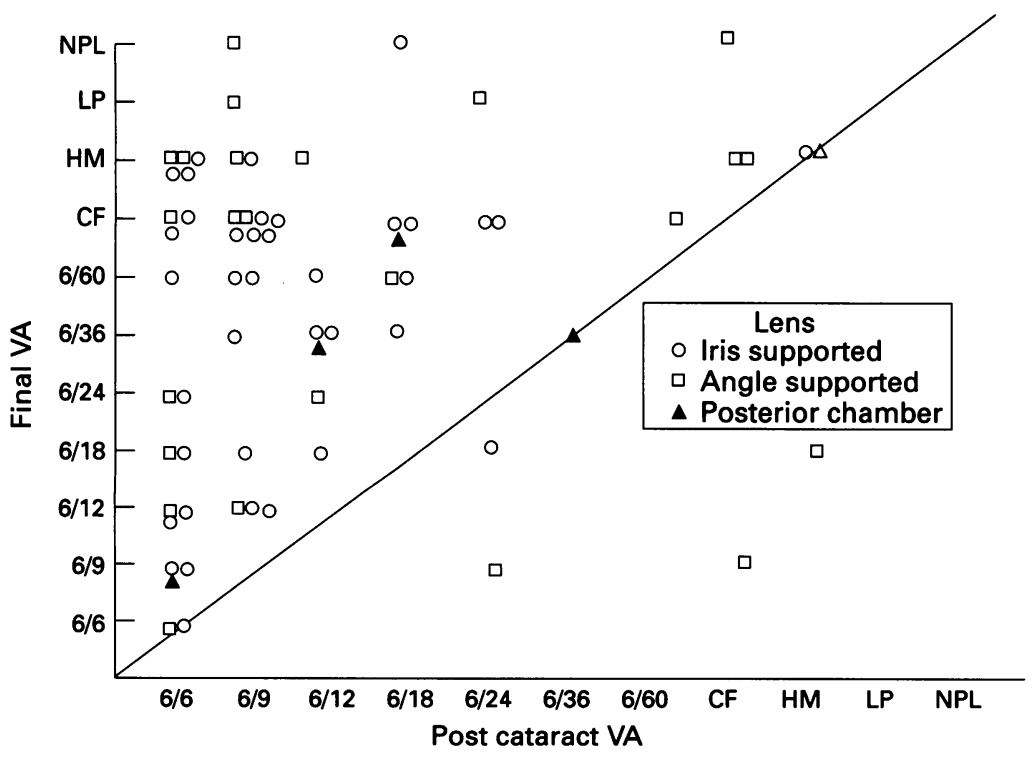

Figure 4 Final visual acuity (VA) after penetrating keratoplasty compared with VA after cataract extraction (post cataract acuity available on 69 eyes only).
Table 4 Causes of corrected visual acuity below 6/60 other than graft failure

Macular degeneration

Glaucoma

Cystoid macular oedema

Cystoid macular oedema + macular degeneration

Cystoid macular oedema + glaucoma

Retinal detachmen

Anterior ischaemic optic neuropathy

Retropupillary membrane

Total

whether earlier and more aggressive surgery for PCO will be of greater and more long term benefit.

In our study we have found similar results to others with regard to post keratoplasty corneal clarity. Our result of $91.4 \%$ graft survival confirms previously reported findings of good corneal clarity at 1 year after penetrating keratoplasty. ${ }^{24}$ Also like other studies the visual results are, however, disappointing with only $20 \%$ achieving a best corrected visual acuity $6 / 12$ or better. A significant number of our patients have been rendered aphakic and often these patients forgo corrective aphakic contact lens wear for either personal reasons or because of medical contraindications. The patient is, however, provided with a 'spare eye' which, if necessary, can undergo secondary lens implantation at a later date. ${ }^{25}$ Another recent study on patient satisfaction after penetrating keratoplasty has revealed the importance of perceived benefit to the patient as well as pregraft expectation in patient satisfaction. Patient satisfaction was not related to a specific high level of visual acuity but more to some improvement especially over the level of acuity in the other eye. ${ }^{26}$ This is of importance in PCO where the potential for attaining a high level of acuity after cataract surgery was significant and may have already been achieved before the onset of corneal oedema. This only goes to emphasise the disappointing levels of visual acuity attained following PK. Nevertheless, the improvement in comfort following PK and the prophylaxis offered against microbial keratitis in a largely elderly population should not be underestimated. Although measures such as bandage contact lens and stromal puncture may aid comfort in the bullous cornea, our results lead us to recommend PK for the treatment of PCO even when IOL removal is required or where macular disease is known to be present.

In some centres PCO is now the commonest primary diagnosis in patients undergoing regrafts. ${ }^{7}$ In our study out of 23 graft failures 11 have been regrafted of which eight remain clear. Our study confirms the findings that graft clarity and visual results are relatively good in regrafts.

Six patients with posterior chamber (PC) lens implantation underwent PK for PCO in our study. In a study of graft survival in four common groups undergoing PK, Price et al found that retained posterior chamber IOLs in PCO had a graft failure rate of $5 \cdot 1 \%$ compared with less than $1 \%$ in the groups of keratoconus, Fuch's dystrophy, or PCO with secondary IOLs. Only PCO with retained anterior 
chamber IOLs fared worse. ${ }^{27}$ All our patients with PC IOLs had significant previous or perioperative disease. There has, however, been a dramatic increase in the use of PC IOLs after cataract extractions. ${ }^{28}$ In our study no PC IOLs were implanted in 1980 , whereas by the end of the decade over 2500 per year were implanted. The incidence of PCO with modern PC IOLs is in the order of $0.1 \% .^{22}$ With the continuing development of cataract surgery techniques, including new lens technology and phakoemulsification with an associated surgical learning curve, PCO is unlikely to disappear. Furthermore, patients with preexisting corneal or inflammatory disease who several years ago would have been left aphakic are now being implanted at the time of cataract surgery. Pseudophakic corneal oedema may yet prove to be a late consequence of modern cataract surgery and not just a reflection of erstwhile lens implants and historical surgical techniques.

1 Vail A, Gore SM, Bradley BA, Easty DL, Rogers CA. Corneal transplantation in the United Kingdom and Republic of Ireland. Br F Ophthalmol 1993; 77: 650-6. Smith RE. An update of the indications for penetrating kerSmith RE. An update of the indications for penetrating ker-

3 Brady SE, Rapuano CJ, Arentsen JJ, Cohen EJ, Laibson PR Clinical indications for and procedures associated with penetrating keratoplasty, 1983-1988. Am f Ophthalmol penetrating keratop

4 Mamalis N, Anderson CW, Kreisler KR, Lundergran MK, Olson RJ. Changing trends in the indication for penetrating keratoplasty. Arch Ophthalmol 1992; 110: 1409-11.

5 Williams KA, Muehlberg SM, Wing SJ, Coster DJ. Th Australian corneal graft registry 1990 to 1992 report, Supplement. Aust NZ Ophthalmol 1993; 21: 14-5.

6 Haamann $P$, Jensen OM, Schmidt P. Changing indications for penetrating keratoplasty. Acta Ophthalmol 1994; 72: 443-6.

7 Rapuanco CJ, Cohen EJ, Brady SE, Arentsen JJ, Laibson PR. Indications for and outcomes of repeat penetrating $\mathrm{PR}$. Indications for and outcomes of repeat pene
keratoplasty. Am $₹$ Ophthalmol 1990; 109: 689-95.

8 Cohen EJ, Brady SE, Leavitt K, Lugo M, Speaker MG, Laibson PR, Artensen JJ. Pseudophakic bullous keratopathy. Am F Ophthalmol 1988; 106: 264-9.

9 Waltman SR. Penetrating keratoplasty for pseudophakic bullous keratopathy. Arch Ophthalmol 1981; 99: 415-6.

10 Waring GO, The 50-year epidemic of pseudophakic corneal oedema. Arch Ophthalmol 1989; 107: 657-9.
11 Bigar F, Sturmer J, Ganzfied R. Pseudophake bullose keratopathie. Klin Monatsbl Aughenheilkd 1988; 192: 453-7.

12 Kervick GN, Shepherd WF. Changing indications for penetrating keratoplasty. Ophthalmic Surg 1990; 21: 227.

13 Roper-Hall MJ, Watts MT. Retention of iris supported lenses at the time of penetrating keratoplasty for pseudophakic corneal oedema. Br f Ophthalmol 1989; 73: 407-9.

14 Hall JR, Muenzler WS. Intraocular lens replacement in pseudophakic bullous keratopathy. Trans Ophthalmol Soc UK 1985; 104: 541-5.

15 Busin M, Arffa RC, McDonald MB, Kaufmann HE. Intraocular lens removal during penetrating keratoplasty for pseudophakic bullous keratopathy. Ophthalmology 1987; 94: 505-9.

16 Smith PW, Wong SK, Stark WJ, Gottsch JD, Terry AC, Bonham RD. Complications of semiflexible closed-loop Bonham RD. Complications of semiflexible closed-loop 1987; 105: 52-7.

17 Insler SM, Kook MS, Kaufman HE. Penetrating keratoplasty for pseudophakic bullous keratopathy associated with semiflexible, closed-loop anterior chamber intraocular lenses. Am F Ophthalmol 1989; 107: 262-6.

18 Kornmehl EW, Steinert RF, Odrich MG, Stevens JB. Penetrating keratoplasty for pseudophakic bullous keratopathy associated with closed-loop anterior chamber intraocular lenses. Ophthalmology 1990; 97: 407-12.

19 Stark WJ, Goodman G, Goodman D, Gottsch J. Posterior chamber intraocular lens implantation in the absence of chamber intraocular lens implantation in the absence of posterio

20 Price FW, Whitson WE. Visual results of suture-fixated posterior chamber lenses during penetrating keratoplasty. Ophthalmology 1989; 96: 1234-40.

21 Apple DJ, Price FW, Gwin T, Imkamp E, Daun M, Casanova $\mathrm{R}$, et al. Sutured retropupillary posterior chamber intraocular lenses for exchange or secondary implantation. [The 12th Annual Binkhorst Lecture, 1988.] Ophthalmology 1989; 96: 1241-7.

22 Johnson SM. Results of exchanging anterior chamber lenses with sulcus-fixated posterior chamber IOLs without with sulcus-fixated posterior chamber IOLs without capsular support in pent

23 Busin $M$, Brauweiler $P$, Boker $T$, Spitznas $M$. Complications of sulcus-supported intraocular lenses with iris sutures, implanted during penetrating keratoplasty after intracapsular cataract extraction. Ophthalmology 1990; 97: 401-6.

24 Binder PS. Secondary intraocular lens implantation during or after corneal transplantation. Am $\mathcal{F}$ Ophthalmol 1985; 99: 515-20.

25 Geggel HS. Intraocular lens implantation after penetrating keratoplasty. Ophthalmology 1990; 97: 1460-7.

26 Williams KA, Ash JK, Pararajasegaram P, Harris S, Coster DJ. Long-term outcome after corneal transplantation. Ophthalmology 1991; 98: 651-7.

27 Price FW, Whitson WE, Marks RG. Graft survival in four common groups of patients undergoing penetrating keratoplasty. Ophthalmology 1991; 98: 322-8.

28 Stark WJ, Sommer A, Smith RE. Changing trends in intraocular lens implantation. Arch Ophthalmol 1989; 107: 1441-4. 